\title{
RELENDO JOSÉ GUILHERME MERQUIOR: 40 ANOS DE FORMALISMO E TRADIÇÃO MODERNA
}

\section{READING JOSÉ GUILHERME MERQUIOR AGAIN: 40 YEARS AFTER FORMALISM AND MODERN TRADITION}

\author{
José Luís Jobim* \\ Universidade Estadual do Rio de Janeiro
}

RESUMO: Reler o livro impactante de José Guilherme Merquior, 40 anos depois de lançado, pode ser uma experiência interessante se compararmos o contexto de hoje com a recepção original nos anos 70. Algumas das observações de Merquior naquela época a respeito da Indústria Cultural ainda são atuais, especialmente aquelas que dizem respeito à relação daquela Indústria com a civilização urbanoindustrial no Ocidente e a marginalização dos tipos de obra de arte que anteriormente ofereciam alguma preparação individual para uma atitude crítica em relação à cultura.

PALAVRAS-CHAVE: Releitura. José Guilherme Merquior. Formalismo e Tradição Moderna.

ABSTRACT: Reading again the groundbreaking book by José Guilherme Merquior 40 years after his first edition may be a very interesting experience if we compare today's context with the original reception in the 1970s. Some of Merquior's remarks then concerning the Culture Industry are still up to date, specially those concerning

\footnotetext{
Doutor em Teoria Literária pela Universidade Federal do Rio de Janeiro (UFRJ). Pós-doutorado em Stanford University. Professor associado IV do Departamento de Ciências da Linguagem na Universidade Federal Fluminense (UFF). Niterói, Rio de Janeiro, Brasil. Professor titular do departamento CULT na Universidade Estadual do Rio de Janeiro (UERJ). Rio de Janeiro, RJ, Brasil. E-mail: jobim@id.uff.br
} 
the relationship of this Industry with urban-industrial civilization in the West and the marginalization of the kinds of works of art that previously offered some personal preparation to introduce people to a critical attitude towards culture.

KEYWORDS: Rereading. José Guilherme Merquior. Formalism and Modern Tradition. 


\section{RELENDO JOSÉ GUILHERME MERQUIOR: 40 ANOS DE FORMALISMO E TRADIÇÃO MODERNA}

Em 1974, quando foi publicado Formalismo e tradição moderna, seu autor já tinha destaque nos jornais e suplementos literários, por sua atuação como crítico e teórico da literatura e das artes, e por sua disposição para assumir posições bem definidas e defendê-las no debate público. Na resenha desse livro para a revista Visão, Muniz Sodré enfatiza os dois lados pelos quais Merquior (1974) ganhou fama: a qualificação acadêmica e a capacidade para a polêmica:

José Guilherme Merquior é hoje não só um dos mais afiados críticos literários do Brasil, mas também um dos mais eruditos, no melhor sentido da palavra. (...) Tudo indica que ele escreveu Formalismo \& tradição moderna ao som de 'pode vir quente que eu estou fervendo' ${ }^{1}$ (SODRÉ, 1974)

Arquivos de jornais e revistas fornecem ao pesquisador de hoje dados mais visíveis sobre aquela época. Por isso, começaremos essa argumentação

1 Para o leitor mais jovem, esclareço a referência. Trata-se de uma música de Erasmo Carlos, de grande sucesso, cujo refrão é o seguinte: "Se você quer brigar/ E acha com isso estou sofrendo?/Se enganou meu bem,/ Pode vir quente que eu estou fervendo!" 
com uma faceta invisível para o leitor de agora: a correspondência recebida por Merquior sobre esse livro.

É importante lembrar que, no sistema cultural brasileiro, a relação epistolar entre autores é fundamental não só para a compreensão de como se estrutura a sociabilidade literária e cultural, mas também porque, pelo menos desde o Modernismo, uma parte significativa do que poderíamos chamar de crítica de intervenção ocorreu através de troca de cartas. Quando lemos a correspondência de Mário de Andrade, por exemplo, verificamos que ele tanto pede opinião a colegas escritores sobre seus escritos literários e críticos, como também recebe pedidos sobre o que seus colegas escreveram. Tudo isso vai se refletir na produção textual posterior, inclusive com a alteração de textos antes de serem publicados.

Aliás, um dos correspondentes de Mário nos anos 1920 também vai enviar carta a Merquior, cinquenta anos depois. Carlos Drummond de Andrade era apenas um jovem, buscando conselhos com um escritor mais velho, nos primórdios do Modernismo, mas nos anos 1970, já era um dos autores de maior prestígio da literatura brasileira. Eis a opinião dele, expressa em correspondência manuscrita de 25 de novembro de 1974 :

'Formalismo e Tradição Moderna' é desses livros que se colocam no centro dos debates sobre arte e cultura e lhe trazem uma luz nova. Tocando no "coração da matéria" com perspicácia, bravura opinativa e excelente equipamento intelectual você abre os olhos de muita gente, que anda por aí perplexa ou iludida. Se não quiserem enxergar... paciência. Você deu o recado - magistralmente ${ }^{2}$

(DRUMMOND DE ANDRADE, 1974)

Fábio Lucas, escrevendo da Universidade de Wisconsin, Madison (EUA), também expressou entusiasmo com o livro, em carta de 6 de dezembro de

2 Agradeço a João Cezar de Castro Rocha e à Editora É Realizações pelo acesso à correspondência inédita que será citada aqui, e que depois estará disponível na republicação da obra de Merquior, sob a supervisão desse crítico e pesquisador. 
1974: “Recebi 'Formalismo e tradição moderna', uma das poucas obras críticas brasileiras que me despertou entusiasmo nos últimos tempos. Principalmente abriu-me o apetite da discussão intelectual" (LUCAS, 1974). Nomeando Merquior como interlocutor de ideias, Lucas explicita: "A sua disposição para o diálogo e para a polêmica aguçou um faro instantâneo como um relâmpago para ir direto ao coração de certos problemas" (LUCAS, 1974) e vai logo comentando uma reflexão de Merquior sobre Hegel, e fazendo observações sobre uma dos ensaios do livro: "Quando você define o kitsch, p. 33, vi o retrato do Barroco. Não lhe ocorreu isso? Ah, o kitsch político: J. Quadros, a Argentina...” (LUCAS, 1974)

Da Fundação Joaquim Nabuco, em Recife, Gilberto Freyre também enviou um telegrama para o Itamaraty, dirigido a Merquior:

"ESTOU CONCLUINDO LEITURA FORMALISMO
TRADIÇAO VERDADEIRAMENTE ENCANTADO
COM SEU MODO AO MESMO TEMPO SERIO ET
ATRAENTE VERSAR ASSUNTO HISTORIA DAR-
TE FILOSOFIA ET TEORIA ESTETICA NO QUE EH
SEM DUVIDA UM LIVRO ADMIRÁVEL ET SOB
CERTOS ASPECTOS ÚNICO EM NOSSA LITERA-
TURA FILOSOFICA"

(FREYRE, 1974)

Mário Chamie, em carta de 7 de fevereiro de 1975, declara:

... ouvi do Antônio Cândido a seu respeito, Merquior, referências que, além de entusiásticas, davam a justa medida do conceito e do respeito invejáveis que você inspira.

E acrescenta, sobre o livro:

Outro assunto: José Pinto, dono da Livraria Informática, me informa que seu livro 'Formalismo e Tradição Moderna' é tão procurado e vende tão bem que ele, 
seguindo norma da livraria que patrocina mesas-redondas, debates etc., pensa (com convidados especiais e selecionados) em dedicar-lhe uma reunião mesmo com sua ausência.

(CHAMIE, 1975)

Claro, para o leitor de hoje entender melhor o impacto daquela publicação, precisaremos ainda falar um pouco mais sobre o seu contexto.

\section{UM POUCO DE CONTEXTO}

O termo formalismo, no Brasil dos anos 1970, serviu como pretexto para muita polêmica. No debate intelectual daquela época, era comum trabalhar com o par opositivo forma e conteúdo. Contrapunham-se, de um lado, os conteudistas, mais interessados nas referências sociais da literatura, e de outro os formalistas, mais interessados na forma em que se constituíam as obras literárias. Como veremos adiante, Merquior vai apresentar uma posição diferente, que pode ser resumida da seguinte maneira: "O formalismo é (...) o nome geral da consciência estética acometida por indiferença ou insensibilidade em relação à problemática da civilização.” (MERQUIOR, 1974, p. 217)

Lembremo-nos de que, no Brasil dos anos 70, estávamos em plena ditadura militar. No Rio de Janeiro, principalmente na Pontifícia Universidade Católica, havia a disseminação de um certo Estruturalismo francês, que podia ser evocado pelos críticos conteudistas de então como exemplo de formalismo. No entanto, o movimento teórico que originalmente se denominou Formalismo na Europa era muito anterior, e Merquior já assinalava isso: “(...) a chamada crítica "estruturalista” francesa dos últimos anos (R. Barthes, T. Todorov, etc.) se considera herdeira dos formalistas de 1920." (MERQUIOR, 1974, 218)

A conexão do Estruturalismo com o Formalismo Russo deu-se graças à publicação de uma antologia de textos selecionados e traduzidos para o francês por Tzvetan Todorov, em 1965, através da qual aqueles teóricos e críticos russos ganharam uma maior notoriedade internacional. Todorov, naquela época, foi membro destacado do grupo de teóricos estruturalistas 
franceses da literatura, embora tivesse nascido na Bulgária. Sua antologia ganhou uma notoriedade muitas vezes superior à de Victor Erlich, que já tinha publicado outra seleção de textos dez anos antes (Russian Formalism: History, Doctrine, de 1955), cuja circulação ficou mais restrita aos eslavistas. No Brasil, aquela antologia francesa, com prefácio e introdução diferentes da edição original, teve mais de uma edição.

Já o Estruturalismo tcheco, anterior ao francês e diferente dele, teve muito menos divulgação e impacto na época. No Brasil, a mesma editora que havia publicado a antologia dos formalistas russos publicou também em 1978 uma antologia dos estruturalistas tchecos (Círculo Linguístico de Praga: Estruturalismo e Semiologia. Porto Alegre: Globo) que não teve o mesmo sucesso. Por isso, é importante chamar a atenção sobre o ensaio denso e instigante que Merquior dedicou a Mukarovsky e seus companheiros de Praga. Aquele crítico e teórico tcheco estava muito longe de fazer parte do cardápio intelectual da época, de modo que a relevância merecida que lhe dá Merquior certamente contribuiu para trazê-lo à cena do debate intelectual entre nós.

Os conteudistas no Brasil daquele momento predominantemente se viam como de esquerda, e, a bem da verdade, foi no próprio ambiente eslavo que se produziram as primeiras críticas àquele Formalismo, inclusive políticas. Leon Trotski (1980), por exemplo, na década de 20, em seu Literatura e revolução (cuja primeira edição brasileira é, não por acaso, de finais dos anos sessenta) já apontava a estreita relação daquele movimento teórico com os futuristas russos, o que, segundo ele, levaria a uma concepção equivocada de que a arte se encontra sempre "em obras de formas puras"3. Essa suposta concepção explicaria a virulência do ataque de Trotski à escola formalista que ele considera "um aborto" ${ }^{4}$, porque, na sua visão, os formalistas, ao proclamarem que a essência da poesia está na forma, teriam reduzido sua tarefa a uma análise essencialmente descritiva e semiestática de elementos da arte vistos como formais, deixando de lado a conexão com o social.

Assim, se a crítica de esquerda nos anos 1970 de algum modo relacionou-se com posições muito anteriores, é importante assinalar aqui que, como

3 Cf. TROTSKI, Leon. A escola de poesia formalista e o marxismo. In: Literatura e revolução. 2. Ed. Rio de Janeiro: Zahar, 1980. p. 143-160.

4 “Tal como é atualmente representada por Chklovsky, Jirmunski, Jakobson e outros, ela [a escola formalista] não passa de insólito aborto.” (p. 144) 
veremos, para Merquior o termo formalismo não terá o mesmo sentido que os conteudistas da época majoritariamente lhe atribuíam. Na verdade, o crítico brasileiro vai dialogar com um pensamento de esquerda muito mais sofisticado do que o do ambiente russo das primeiras décadas do século vinte: o da chamada Escola de Frankfurt.

Quando se trata do trabalho de crítica da obra artística, Merquior não deixa de situar o próprio método analítico formalista em seu contexto histórico, atribuindo sua origem a Heinrich Wölfflin, com a ressalva de que o impulso de valorização da forma em um sentido isolacionista já ocorria antes, mas ainda não havia sido sistematizado dessa maneira:

A inclinação propriamente formalista da análise formal consiste, portanto, em isolar a forma de toda articulação com o significado cultural da obra de arte, tanto no que se refere à cultura material quanto no que concerne à cultura espiritual. Cronologicamente - e isso é que parece dar razão à idéia conteudística de que estudo de forma e formalismo se confundem essa inclinação coincide com a própria emergência da análise da forma, em Wölfflin.

(MERQUIOR, 1974, p. 189)

Sem dúvida, não podemos ignorar a relação de Merquior com o chamado Estruturalismo francês, relação que não se limitou à discussão sobre os fundamentos da teoria literária produzida pelo grupo considerado "Estruturalista" (Barthes, Todorov, Greimas, Genette etc.), à época. Sua proximidade com Claude Lévi-Strauss pode ser explicar a adoção de um tom ainda predominantemente conciliatório, não obstante as críticas duras ao trabalho teórico de Todorov e Jakobson e dos supostos estruturalistas brasileiros de então, que expressam algumas das reservas que já tinha àquele movimento teórico.

De fato, Merquior foi aluno de Lévi-Strauss, escreveu um livro (A estética de Lévi-Strauss) sobre seu pensamento, e manteve com ele um diálogo epistolar que será publicado em breve, na coleção de obras de Merquior organizada por João Cezar de Castro Rocha. 
Em Formalismo e tradição moderna, escolheu atacar mais agressivamente apenas o que se produzia no Brasil em nome desse Estruturalismo, e mesmo assim somente em breves passagens. No ano seguinte, voltou ao assunto em outro livro: O estruturalismo dos pobres e outras questões.

Ainda em Formalismo e tradição moderna, Merquior diplomaticamente argumenta que o "verdadeiro estruturalismo" (seja lá o que isso quer dizer) não pode apresentar a tendência a isolar a literatura do vínculo concreto com a cultura histórica, não podendo, portanto, descender da estética do formalismo russo, a não ser em alguns pontos particulares, como a atenção ao texto, que seria compartilhada com muitos outros movimentos teóricos, como o New Criticism, a Stilkritik suíço-alemã, o neoaristotelismo de Chicago, entre outros. (MERQUIOR, 1974, p. 218)

De todo modo, as referências ao Estruturalismo francês continuarão a aparecer em sua obra, nas décadas seguintes, tanto em livros que tematizam autores específicos, como Michel Foucault ou O niilismo da cátedra (1985) quanto em grandes panoramas que conjugam história intelectual e crítica de ideias, como De Praga a Paris: uma crítica do estruturalismo e do pensamento pós-estruturalista. Este último livro, curiosamente, foi primeiro publicado em inglês (1986), na Verso (uma tradicional editora de esquerda), depois em espanhol (no México, na prestigiosíssima editora Fondo de Cultura Económica), para somente em 1991 sair em português, no Brasil.

É interessante aqui assinalar que, desde o momento em que Merquior escreve Formalismo e tradição moderna até 1986, ele vai modificar seu estilo, não só diminuindo o número de referências bibliográficas explícitas ao longo do texto, mas também tentando o mais possível usar um vocabulário de circulação mais ampla. Ele também passa a utilizar um tipo de redação mais fácil para a compreensão de um público bem informado mas não exatamente especializado nos temas abordados.

Formalismo e tradição moderna, originalmente coeditado pela Forense Universitária com a Editora da Universidade de São Paulo, é um livro com menos concessões, fazendo uso de uma argumentação cerrada e uma profusão de citações diretas, alusões e notas bibliográficas, que, na boa tradição acadêmica, tornam claro para o leitor os autores com os quais Merquior dialoga, ajudando a compreender com maior precisão as suas referências. 
Por outro lado, além do Estruturalismo francês, há também nesse livro um diálogo intenso com ideias fundamentais dos frankfurtianos, diálogo que já tinha sido desenvolvido anteriormente em Arte e Sociedade em Marcuse, Adorno e Benjamin (1969), e que faz parte do horizonte dos críticos da época, constando não somente do repertório de críticos paulistas de formação mais sociológica, mas também da bibliografia de críticos de outros perfis, como Eduardo Portella, em cuja tese de doutorado (1970) são listados Adorno, Marcuse e Benjamin (PORTELLA, 1974, p. 63).

É em diálogo com os frankfurtianos que Merquior escolhe o kitsch como alvo de interesse. Discutir o kitsch era moda na época, mas Merquior retoma o termo como designativo de objetos, obras de arte ou espetáculos de mau gosto, mais ligados à cultura de massa, porém pretensiosos. Para ele, a sociedade massificada, comprimida nas cidades grandes, seria particularmente vulnerável a esses produtos. Desenvolvendo sua argumentação na direção contrária a certos críticos de então, que buscavam justificar a arte kitsch, a partir de uma posição em que consideravam que o mau gosto e a pretensão deveriam ser aceitos como parte importante do cenário contemporâneo, Merquior acusa esses críticos de tentarem neutralizar o sabor de acusação e denúncia que fundamentava o uso do termo kitsch para desqualificar obras que não merecessem ser bem consideradas. Para ele, a justificação do kitsch baseia-se na alienação feita estética - e na estética da alienação. Daí sua condenação veemente aos intelectuais que ele chama de kitschistas:

Os intelectuais kitschistas são intelectuais que abjuraram a fé nos valores da cultura. (...) A tática desses renegados consiste em xingar a alta cultura de repressiva. Reivindicando indulgência para com os 'prazeres' alienados do 'homem comum', posando de 'democratas' hostis ao 'elitismo' da alta cultura, os kitschistas se fazem apóstolos da tolerância. Mas nós já vimos bem o que essa tolerância filistina encerra em matéria de agressividade. Essas 'defesas' ideológicas do homem da rua e do gosto 'popular' só servem para dar razão àquele epigrama dos Minima moralia, de Adorno: 'O 
burguês é tolerante: seu amor aos homens como são reflete o seu ódio ao homem como ele deve ser'.

(MERQUIOR, 1974, p. 29)

Diga-se de passagem, a adoção de um sentido desqualificador para o termo kitsch torna ainda mais pesada a afirmativa de Merquior sobre a crítica estruturalista de base francesa dessa época: "99\% de toda crítica literária dita estruturalista é kitsch".

Para Merquior, a cultura de massa seria um derivado da invasão, pela sociedade de consumo, do terreno da arte e dos objetos culturais, gerando o gosto kitsch. Essa invasão geraria distorções, tanto no caso da "alta cultura" quanto no da arte "popular", que deixaria de ser autenticamente popular. Para ele, na contemporaneidade, a alta cultura, em função de seu estetismo radical, estaria mais vulnerável à kitschização, mas a raiz do que há de intrinsecamente aristocrático na tradição moderna é o compromisso da arte com a crítica da cultura. Por oposição à "cultura autêntica", a "cultura de massa" aspiraria apenas a entreter, e os objetos produzidos por ela seriam tão consumidos quanto os bens materiais mais utilitários.

O estetismo da grande arte moderna, para Merquior, não significava um afastamento do social, mas uma tentativa de questionamento das formas socialmente vigentes. Essa é uma opinião convergente com a de outro crítico importante da época que também chamava a atenção para a historicidade e a socialidade das formas literárias: Antonio Candido. Merquior considera que a literatura é um produto da inteligência humana inserida em um contexto histórico-social, e não de algum elemento biológico ou físico, mesmo no caso de gêneros, como a lírica, supostamente mais ligados a um subjetivismo mais acentuado. Ele argumenta que a lírica moderna responde tanto a uma história interna da arte literária, que paga tributo ao caráter social das formas artísticas, quanto externa, em resposta às grandes transformações sociais e culturais do Ocidente.

Para Merquior, a tradição da arte moderna soube honrar o imperativo ético-estético da grandeza; soube escapar à sina da arte na dispersão dos valores da cena contemporânea, que é a degradação do estetismo em kitsch. O problema seria que a cultura de massa, ao disseminar um gosto por objetos 
artísticos pré-formatados, reduziu o público potencial da grande arte, que passou a ser considerada difícil, hermética e outras coisas parecidas, justamente por não se reduzir aos padrões genéricos com os quais a sociedade de consumo já habituara o público de massa, impondo um sistema de produção que basicamente consistiria em mais do mesmo.

No entanto, se a busca de novas formas e conteúdos causou uma recusa do público de massa a um tipo de arte que passou a ser vista como "hermética", Merquior lembra que o ideal de incomunicabilidade ostentado pelas letras contemporâneas é, pelo menos desde Mallarmé, uma estratégia cultural, dirigida com toda razão contra a suposta "comunicabilidade" fácil da literatura de massa. Assim, para ele: "Seria completamente errôneo tomar essa guerrilha contra a prostituição da comunicação verbal por um repúdio literal e inumano do comunicar."

\section{FORMALISMO, SOCIEDADE URBANO-INDUSTRIAL E MARGINALIZAÇÃO DA ARTE}

Por tudo o que dissemos até agora, o leitor já terá percebido que há um núcleo na argumentação de Merquior: a ideia de que a civilização urbano-industrial vem gerando espécies de arte e de comunicação "desumanizantes", por oposição a uma arte que serviria a um processo formativo e crítico do indivíduo em relação ao mundo em que se insere.

Merquior presume como finalidade a formação personalizada de sujeitos críticos através do contato com objetos artísticos estruturados criticamente em relação ao seu contexto. Essa formação implicaria também uma assimilação "espontânea", pelo sujeito, do saber e da tradição crítica corporificados nos objetos da alta arte, em contraste com a submissão despersonalizada aos modelos pré-formatados da cultura de massa. Seria o encontro do público com essas manifestações culturais que tornaria possível a elaboração de novos sentidos para a vida.

Por oposição à "cultura autêntica", Merquior considera que a "cultura de massa" aspira apenas a entreter, e que os objetos produzidos por ela são tão consumidos quanto os bens materiais mais utilitários. Para ele, a "cultura de 
massa" é um derivado da invasão, pela sociedade de consumo, do terreno da arte e dos objetos culturais, gerando o gosto kitsch. Essa invasão geraria distorções, tanto no caso da "alta cultura" quanto no da arte "popular", que deixaria de ser autenticamente popular.

Talvez algum leitor já tenha identificado, nesse ponto, um certo substrato de sentido de autenticidade que pode ser também comparado historicamente com propostas de autenticidade "de raiz" remontando a projetos artísticos oitocentistas para coleta de narrativas e poemas "anônimos" ou atribuídos a bardos e autores supostamente autênticos. Este tipo de proposta abrange desde The Minstrelsy of the Scottish Border (1802), passando pelos contos de Grimm, ou, no caso brasileiro, por José de Alencar (lembremo-nos de $O$ nosso cancioneiro [1874]), chegando até o trabalho de Mário de Andrade. Há aí uma certa ideia de recuperação de um núcleo de sentido original, manifestado no passado de um povo e articulado nas formas artísticas. Quanto mais anônimas essas formas, melhor, porque mais representativas de uma suposta enunciação popular, com um sujeito autoral socialmente coletivo. Assim, autêntico, nesse viés de sentido, seria o que, na contemporaneidade, mantém um núcleo artístico orgânico, uma gema original inalterada diante da massificação dos modelos prontos.

Em oposição à autenticidade, o kitsch se apoiaria na automatização da experiência artística, na abdicação do senso crítico, na reação de um público dominado pelos mecanismos de massificação. Por isso seria importante a autonomia mesma do juízo estético, e, para argumentar nessa direção, Merquior traz a sua interpretação daquele livro que, na obra de Kant, é considerado o núcleo de sua reflexão sobre estética: a Crítica do juízo (1790). Na visão de Merquior, Kant teria recusado a relativização do julgamento sobre obras de arte, expressa no ditado "gosto não se discute". Como os fruidores da arte não se contentariam em produzir juízos válidos apenas para cada indivíduo, de algum modo o julgamento de cada um solicitaria a aprovação de todos os demais, pois, a partir da proposta de que o desfrute da arte deve ser desinteressado, o prazer proporcionado pela obra artística não seria derivado apenas de condições individuais absolutamente privadas, mas teria relação com o senso comum, naquilo em que o senso comum, como “juízo sem conceito", vai muito além do indivíduo. 
Ao mesmo tempo em que considera a Crítica do juízo (1790) como marco decisivo da legitimação da autonomia da arte, Merquior também credita a Kant a tendência posterior a transformar a arte em puro jogo abstrato, sem raízes no drama da cultura e sem lançar luz sobre os problemas da existência.

Assim, se os artistas e o público gradualmente se liberam de seguir os parâmetros vigentes até o neoclassicismo, e passam, a partir da Crítica do juízo, a reconhecer a autonomia da função estética, essa autonomia também serviu de argumento de base para o surgimento de um tipo de arte que seria puro jogo abstrato, sem raízes sociais e sem lançar luz sobre os problemas da existência. A radicalização da autonomia poderia, então, significar um exílio da densidade do mundo, transformando a arte em mero jogo, evasivo em relação ao contexto social em que se insere (MERQUIOR, 1974, p. 159):

Entre essa destinação histórica ao ludismo evasionista e a natureza íntima da arte, uma tensão dialética logo se estabeleceu. Astutamente, a nova arte, que o novo ethos burguês tentaria reduzir a mero "recreio do espírito", passa a empregar seu próprio solipsismo contra a cultura que a marginaliza. Parte da essência do romantismo reside na utilização desse impulso de acentuação do peculiarmente estético como estratégia da crítica da cultura vigente.

(MERQUIOR, 1974, p. 160)

Adepto da concepção weberiana de desencantamento do mundo, a partir do Iluminismo, Merquior sustenta que também a autonomia da esfera estética em relação à religiosa foi importante, mas acrescenta que o utilitarismo e o materialismo predominantes na sociedade urbano-industrial vão gerar também, como contrapartida, um desejo de revitalização de visões de mundo totalizantes de cunho transcendental, para compensar os efeitos traumáticos das transformações da consciência religiosa diante dessa nova sociedade urbano-industrial:

A atribuição de uma tarefa sacralizadora à arte, em conexão com o repúdio ao utilitarismo da moral bur- 
guesa, se exprime com perfeita nitidez na palavra de Fr. Schlegel: 'a poesia, em sua aspiração de infinito, em seu desdém pelo útil, possui a mesma finalidade e as mesmas antipatias que a religião'; e a avidez com que o círculo dos Schlegel sorveu a filosofia de Fichte demonstra quanto era intensa a demanda por totalizações ideológicas suplementares.

(MERQUIOR, 1974, p. 160)

Poderíamos dizer, aqui, que a valorização por Merquior de Matthew Arnold, autor cuja faceta religiosa já estava bem fora do âmbito de interesse dos críticos nos anos 1970, guarda um paralelo com essas totalizações ideológicas. Isso porque Merquior claramente se identifica com a valorização da literatura promovida por Arnold, em um movimento contra "a secura ético-estética do homo oeconomicus vitoriano".

De fato, no capítulo dedicado ao sesquicentenário de Matthew Arnold, Merquior atribui ao crítico britânico uma atitude que é também dele: considerar o texto literário como "arma de uma crítica da civilização" (MERQUIOR, 1974, p. 148-149). O crítico brasileiro poderia assinar embaixo da ideia arnoldiana da literatura como agregadora de uma paideia, ou seja, como fonte de valores de raiz que se contraporiam à nova civilização do trabalho mecânico, espiritualmente mutilador. Aliás, o próprio Merquior poderia ser evocado em sua formação intelectual como exemplo de uomo universale, cujo processo de autoformação guarda relação com os valores da Bildung weimariana (MERQUIOR, 1974, 149). Se esses valores eram vistos como anacrônicos em uma sociedade de consumo cada vez mais massificada, a denúncia renovada dos males que se instalavam é uma das facetas mais reiteradas do trabalho de Merquior.

De algum modo, revendo o passado recente, podemos dizer que a tradição da arte moderna substituiu o substrato religioso por um lugar vazio, a ser preenchido conforme as conveniências do momento. Como resultado da ausência de um conteúdo (ou religioso ou idealizado) que fornecesse uma direção de sentido para a criação do artista, alternativamente se apresentou a expressão do sujeito autoral como núcleo autêntico e original daquela 
criação. Manifesta-se, assim, o pressuposto de que criar é fazer emergir de um sujeito intransitivo um produto artístico cuja gênese ocorre no próprio autor, colocando em segundo plano os fatores contextuais.

A partir disso, a obra pode ser vista como manifestação do sujeito singular e único que através dela se exprime, e valorizada de acordo com o que oferece como materialização da riqueza desse sujeito, e não mais como fruto do zeitgeist, do "espírito do tempo".

Se, por um lado, esta posição "subjetivista", representada no pensamento estético de Benedetto Croce tinha mérito na sua participação reativa contra um certo reducionismo, generalizado na segunda metade do século XIX, que visava interpretar a obra artística como derivada do "espírito do tempo", por outro lado recaía também em posições reducionistas, mas diametralmente opostas. A valorização da experiência viva do sujeito singular, tanto na criação quanto na fruição da obra, nessa segunda posição, é vista como expressão vibrante da riqueza e energia do sujeito singular, que passa então a ser matriz de tudo:

A arte isolada, a arte vestal da estética croceana é uma atividade estanque, resultante de uma 'faculdade' estanque (a intuição-expressão), correlato mental do agir insulado do produtor moderno. Sobretudo, essa arte distilada representa a versão estética do pensar não menos ilhado do especialista, modelo da pesquisa científica inconsciente das suas raízes culturais."

(MERQUIOR, 1974, p. 174)

Assim, enquanto a interpretação da obra como exemplo encarnado do "espírito" de seu tempo gerou um determinismo taineano ou um positivismo pseudo-sociológico, a interpretação da arte como expressão de um subjetivismo absoluto e intransitivo resultou na abertura para uma concepção de arte como expressão de um impulso vital, mas desconectado do universo circundante. Claro, ambos os extremos são redutores da complexidade da relação da arte com os criadores e receptores dela.

No que diz respeito às ligações do pensamento estético com correntes filosóficas contemporâneas, é muito interessante a hipótese de Merquior de 
que, a partir das tensões e dilemas da Primeira Grande Guerra, coloca-se em xeque a tipologia perspectivista das "visões-do-mundo" e há um retorno ao projeto de "filosofia como ciência rigorosa". Para Merquior, Edmond Husserl será fundamental na elaboração de uma teoria em que a vivência do sujeito, processada para determinar essências por trás do fluxo vivencial, pode apresentar-se como instância apodítica, a partir da qual se demonstraria o que é possível conhecer.

Lembramos que, no Rio de Janeiro dos anos 1970, havia intensa discussão sobre a obra de Martin Heidegger (que foi, como se sabe, aluno de Husserl), no campo dos estudos literários. Eduardo Portella, como crítico e diretor da editora Tempo Brasileiro, já havia publicado traduções pioneiras, feitas pelo professor Emanuel Carneiro Leão, da Introdução à metafísica (1966) e de Sobre o Humanismo (1967), além de ter escrito um artigo na Revista Tempo Brasileiro (número 13/14), intitulado "Quem tem medo de Martin Heidegger”, em 1967. No ano da publicação de Formalismo e tradição moderna, Portella publicou em livro sua tese de doutorado (defendida em 1970), Fundamento da investigação literária, e até o fim dessa década, a pós-graduação em Teoria Literária da Universidade Federal do Rio de Janeiro tinha como bibliografia, além dos livros de Portella, a tradução portuguesa de O poético, livro do filósofo Mikel Dufrenne (1969), cuja obra principal, Fenomenologia da experiência estética (1953), foi um desdobramento do pensamento husserliano para as artes.

Merquior tem uma hipótese clara para o momento em que se origina a marginalização da arte: "A matriz histórica da marginalização da arte foi a instalação da sociedade urbano-industrial no século XIX." (MERQUIOR, 1974, p. 159). Para ele, essa marginalização teria continuidade no momento em que escrevia, porque a adoção do que ele chama de impulso formalista pelos seus contemporâneos implicaria a tendência a evitar significações mais densas ou a renunciar a produzir e usufruir de formas artísticas mais vivas, isto é, mais articuladas com os problemas centrais da cultura. Como seu livro tem duas referências no título Formalismo e tradição moderna, cabe agora perguntar: e a tradição moderna? 


\section{TRADIÇÃO MODERNA}

Merquior caracteriza a tradição moderna como o conjunto de tendências estilísticas surgidas desde cerca de um século e meio atrás e, de forma esquemática, marcadas por dois aspectos: “a) a reação crítica contra os modos de vida impostos pela sociedade urbano-industrial; e b) a fidelidade a uma poética essencialmente distinta das coordenadas estéticas vigentes durante a precedente era clássico-romântica." (MERQUIOR, 1974, p. 187).

Ele assinala a sobrevivência, desde 1850 , de traços românticos na arte contemporânea, em permanente conflito com essa tradição. Como resultado, esses traços podem ou ser incorporados produtivamente à arte moderna, sendo submetidos a uma lógica na qual eles se transformam em outra coisa, ou permanecer como "resíduo" inassimilado, como um "vírus esterilizante". "Vírus esterilizante" por quê? Porque, tendo perdido a função que tinham no sistema anterior, e a relação com a vida de então, teriam-se convertido em fontes de formalismo, servindo apenas para manter ou reforçar os "fatores de insensibilidade da arte aos problemas da cultura contemporânea" (MERQUIOR, 1974, p. 187-188).

Para Merquior, depois de entrarem em cena as elites burguesas, a desintelectualização e vulgarização da arte se articularam com outro preconceito romântico: o entendimento da originalidade como absolutamente oposta à tradição e às convenções. Alternativamente, ele prefere pensar a tradição como integração superatória de uma forma socialmente vigente, ou seja, como algo que está ligado a um estilo artístico enraizado vitalmente na sociedade, e, a partir desse enraizamento vital, consegue fazer emergir uma inovação, que não prescinde das raízes que lhe dão sentido. (MERQUIOR, 1974, p. 210).

A tradição moderna, segundo Merquior consistiria no complexo estilístico que caracteriza a era pós-romântica, concretizando-se inicialmente, entre outros, em Baudelaire, Flaubert, Dostoievsky, Wagner, na plástica impressionista, etc. Predominaria até os anos 1970 do século passado, através de seus descendentes, derivados ou sucessores. (MERQUIOR, 1974, p. 217)

Para Merquior, como a arte pode dizer algo não sabido (talvez pressentido, mas não propriamente conhecido) sobre a cultura e a sociedade, ela pode também reivindicar uma função gnoseológica importante, embora diferente 
de outras modalidades de conhecimento. O período que engloba a tradição moderna seria particularmente rico, com o antagonismo entre a grande arte e as tendências culturais dominantes:

Ora, os gestos estilísticos com que a arte entra em conflito com os rumos da civilização são outras tantas iluminações críticas do quadro sócio-cultural; ao rebelar-se contra a orientação dos costumes, contra os valores em curso, as obras de arte aclaram de forma original (às vezes, pioneira) a própria sociedade. Longe de "refletir" simplesmente a moldura social, elas proporcionam às ciências humanas um testemunho inédito sobre a sua evolução.

(MERQUIOR, 1974, p. 244)

A força da (grande) literatura, para ele, se encontraria na superação do uso verbal cotidiano e utilitário, que remeteria a sentidos pragmáticos. Produto de um impulso para o conhecimento, de natureza diferente do científico (isto é, sem as suas concepções e métodos), a literatura geraria conhecimento "pela oblíqua refração da plenitude do real nos crespos da mesma linguagem que a sonegara” (MERQUIOR, 1974, p. 245).

Para Merquior, escrever, mesmo para os que têm a ilusão de serem responsáveis absolutos pela origem e pelo controle de suas obras, é inscrever-se em redes histórico-sociais de sentidos e o grande desafio do momento em que escreveu Formalismo e tradição moderna era tratar da crise da cultura moderna (MERQUIOR, 1974, p. 61). E isso só poderia ser feito se o crítico soubesse ler a história no texto poético, em vez de dissolvê-lo na história (MERQUIOR, 1974, p. 53). Se, como ele diz, "nada existe no poema que não tenha existido antes na história da cultura, a não ser o próprio poema" (MERQUIOR, 1974, p. 132), então a atenção ao quadro mais geral, para ele, não deveria ocorrer em detrimento do objeto artístico, porque, embora esse objeto sempre pague tributo à tradição em que se insere, ele também representa uma configuração única, que deve ser apreciada em suas peculiaridades. Creio que esse ponto de vista permanece atual e relevante para o leitor de hoje, 40 anos depois da sua publicação original. Vamos, então, reler José Guilherme Merquior. 


\section{REFERÊNCIAS}

CHAMIE, Mário. Carta datilografada a José Guilherme Merquior. São Paulo, 7 de fevereiro de 1975 .

DRUMMOND DE ANDRADE, Carlos. Carta manuscrita a José Guilherme Merquior. Rio de Janeiro, 25 de novembro de 1974.

DUFRENNE, Mikel. O poético. Porto Alegre: Globo, 1969.

FREYRE, Gilberto. Telegrama n. 319 - 07 out. 1974.

LUCAS, Fábio. Carta datilografada a José Guilherme Merquior. Madison, Wisconsin (USA), 6 de dezembro de 1974.

MERQUIOR, José Guilherme. Formalismo e tradição moderna; o problema da arte na crise da cultura. Rio de Janeiro/São Paulo: Forense Universitária/ EDUSP, 1974.

PORTELLA, Eduardo. Fundamento da investigação literária. Rio de Janeiro: Tempo Brasileiro, 1974.

SODRÉ, Muniz. A crítica da falsa cultura. Revista Visão, p. 96, nov, 1974.

TROTSKI, Leon. A escola de poesia formalista e o marxismo. In: Literatura e revolução. 2. Ed. Rio de Janeiro: Zahar, 1980. p. 143-160. 